\title{
Communication \\ Risk Factors of Daptomycin-Induced Eosinophilic Pneumonia in a Population with Osteoarticular Infection
}

\author{
Laura Soldevila-Boixader ${ }^{1,2}$, Bernat Villanueva ${ }^{1}$, Marta Ulldemolins ${ }^{1}{ }^{(}$, Eva Benavent ${ }^{1,2}{ }^{\oplus}$, Ariadna Padulles ${ }^{3}$, \\ Alba Ribera ${ }^{1,2}$, Irene Borras ${ }^{1}$, Javier Ariza ${ }^{1,2,4}$ and Oscar Murillo ${ }^{1,2,4, *}$ \\ 1 Infectious Diseases Service, IDIBELL-Hospital Universitari Bellvitge, Feixa Llarga s/n, Hospitalet de \\ Llobregat, 08907 Barcelona, Spain; laura.soldevila@bellvitgehospital.cat (L.S.-B.); \\ bvillanueva@bellvitgehospital.cat (B.V.); mulldemolins@bellvitgehospital.cat (M.U.); \\ eva.benavent@bellvitgehospital.cat (E.B.); ARibera@scias.com (A.R.); Iborras@scias.com (I.B.); \\ jariza@bellvitgehospital.cat (J.A.) \\ 2 Bone and Joint Infection Study Group of the Spanish Society of Clinical Microbiology and Infectious \\ Diseases (GEIO-SEIMC), 28003 Madrid, Spain \\ 3 Pharmacy Department, IDIBELL-Hospital Universitari Bellvitge, Feixa Llarga s/n, Hospitalet de Llobregat, \\ 08907 Barcelona, Spain; apadulles@bellvitgehospital.cat \\ 4 Spanish Network for Research in Infectious Diseases (REIPI RD16/0016/0003), Instituto de Salud Carlos III, \\ 28029 Madrid, Spain \\ * Correspondence: omurillo@bellvitgehospital.cat; Tel.: +34-93-260-7625
}

\section{check for}

updates

Citation: Soldevila-Boixader, L.; Villanueva, B.; Ulldemolins, M.; Benavent, E.; Padulles, A.; Ribera, A.; Borras, I.; Ariza, J.; Murillo, O. Risk Factors of Daptomycin-Induced Eosinophilic Pneumonia in a Population with Osteoarticular Infection. Antibiotics 2021, 10, 446. https://doi.org/10.3390/

antibiotics 10040446

Academic Editor: Maria Mezzatesta

Received: 26 February 2021

Accepted: 14 April 2021

Published: 16 April 2021

Publisher's Note: MDPI stays neutral with regard to jurisdictional claims in published maps and institutional affiliations.

Copyright: (c) 2021 by the authors. Licensee MDPI, Basel, Switzerland. This article is an open access article distributed under the terms and conditions of the Creative Commons Attribution (CC BY) license (https:// creativecommons.org/licenses/by/ $4.0 /)$.
Abstract: Background: Daptomycin-induced eosinophilic pneumonia (DEP) is a rare but severe adverse effect and the risk factors are unknown. The aim of this study was to determine risk factors for DEP. Methods: A retrospective cohort study was performed at the Bone and Joint Infection Unit of the Hospital Universitari Bellvitge (January 2014-December 2018). To identify risk factors for DEP, cases were divided into two groups: those who developed DEP and those without DEP. Results: Among the whole cohort $(n=229)$ we identified 11 DEP cases $(4.8 \%)$ and this percentage almost doubled in the subgroup of patients $\geq 70$ years $(8.1 \%)$. The risk factors for DEP were age $\geq 70$ years (HR 10.19, 95\%CI 1.28-80.93), therapy $>14$ days $(7.71,1.98-30.09)$ and total cumulative dose of daptomycin $\geq 10 \mathrm{~g}(5.30,1.14-24.66)$. Conclusions: Clinicians should monitor cumulative daptomycin dosage to minimize DEP risk, and be cautious particularly in older patients when the total dose of daptomycin exceeds $10 \mathrm{~g}$.

Keywords: daptomycin; eosinophilic pneumonia; risk factors

\section{Introduction}

Daptomycin is a cyclic lipopeptide antibiotic approved for use against complicated skin and soft tissue infection, Staphylococcus aureus bacteremia and right-sided infective endocarditis. However, daptomycin has become widely used also in staphylococcal osteoarticular infections because of its remarkable anti-biofilm activity. Indeed, current guidelines advise for its use mainly as an initial induction course of intravenous antimicrobial therapy and often in combination with other antibiotics to avoid the appearance of resistance [1,2]. In this setting, the use of daptomycin for prolonged periods should be balanced between the potential benefits in the outcome and the risk of adverse events [3-5].

Although daptomycin has proven safety, daptomycin-induced eosinophilic pneumonia (DEP) is a rare but severe adverse effect $[6,7]$. This toxicity is partially related to the usual daptomycin uptake by pulmonary surfactant in the alveoli, which may lead to concentrations high enough to cause injury but also to impair its efficacy; in fact, daptomycin is not recommended to treat pulmonary infections. Despite the fact that the pathophysiology is not totally clear, it seems that DEP is an antigen-mediated process in which alveolar macrophages and T-cells may be activated, which then release interleukin-5 that causes eosinophil production and migration to the lungs. Additionally, alveolar macrophages 
can also excrete cytokines that selectively recruits eosinophils, which may promote further eosinophil accumulation into the lungs [8,9].

Since the introduction of daptomycin, while some cases of DEP have been reported, these have only described the most common clinical manifestations and outcome [10-13]. To date, therefore, we do not know which factors are associated with DEP and thus, in the present study we aimed to determine the risk factors for developing DEP.

\section{Results}

In total, 229 cases received at least one dose of daptomycin and among them, $11(4.8 \%)$ had DEP; a comparison of both groups in regard with main clinical and analytical characteristics is presented in Table 1. All DEP cases underwent a chest X-ray while on daptomycin therapy, which showed peripheral lung infiltrates (alveolar or interstitial), and only one patient had a CT scan that showed radiological findings of organizing pneumonia. In contrast, only $26 \%$ cases $(57 / 218)$ of the remaining cohort underwent a chest X-ray, which was considered similar to the baseline one. Of interest, the performance of a chest X-ray significantly increased in accordance with the length of daptomycin therapy, ranging from $21 \%$ in cases treated less than 7 days to $42 \%$ in those treated more than 14 days $(p=0.005)$. With regard to the age of patients, cases aged $\geq 70$ years underwent a chest $\mathrm{X}$-ray during daptomycin therapy in greater proportion than younger patients ( $31 \% \mathrm{vs}$. $24 \%$, respectively).

Table 1. Analysis of risk factors for daptomycin-induced eosinophilic pneumonia (DEP).

\begin{tabular}{|c|c|c|c|c|}
\hline & $\begin{array}{c}\text { Cases with DEP } \\
\quad n=11\end{array}$ & $\begin{array}{c}\text { Cases without DEP } \\
\qquad n=218\end{array}$ & HR (95\% CI) & $p$-Value \\
\hline Age (median, IQR) & $77.4(71.3-85.5)$ & $69.7(55.6-78.1)$ & $1.06(1.01-1.12)$ & 0.042 \\
\hline$<70$ years & & & 1 & \\
\hline$\geq 70$ years & $10(91)$ & $108(50)$ & $10.19(1.28-80.93)$ & 0.028 \\
\hline Female & $5(45)$ & $104(48)$ & $0.91(0.27-3.08)$ & 0.884 \\
\hline \multicolumn{5}{|l|}{ Comorbidities } \\
\hline Charlson score (median, IQR) & $5(4-7)$ & $4(2-5)$ & $1.31(1.03-1.67)$ & 0.031 \\
\hline Chronic heart disease & $3(30)$ & $27(12)$ & $2.65(0.66-10.62)$ & 0.168 \\
\hline Chronic pulmonary disease & $3(30)$ & $20(9)$ & $3.71(0.91-15.12)$ & 0.067 \\
\hline Chronic kidney disease & $2(20)$ & $56(26)$ & $0.64(0.13-3.07)$ & 0.579 \\
\hline \multicolumn{5}{|l|}{ Analytical data (baseline) } \\
\hline Creatinine $(\mu \mathrm{mol} / \mathrm{L})$ & $62(49-70)$ & $72(57-105)$ & $0.98(0.960-1.005)$ & 0.134 \\
\hline Leucocytes $\left(\times 10^{9}\right.$ cells $\left./ \mathrm{L}\right)$ & $10.1(7.3-11)$ & $9.4(7.2-12.3)$ & $0.965(0.829-1.122)$ & 0.640 \\
\hline Eosinophils (cells $/ \mu \mathrm{L}$; median, IQR) & $130(30-230)$ & $100(30-240)$ & $0.99(0.996-1.003)$ & 0.709 \\
\hline \multicolumn{5}{|l|}{ Analytical data (end of treatment) } \\
\hline${ }^{2}$ Creatine kinase $(\mathrm{mkat} / \mathrm{L})$ & $0.68(0.31-0.89)$ & $0.87(0.54-1.85)$ & $0.81(0.498-1.316)$ & 0.395 \\
\hline C-reactive protein (mg/L) & $223(120-315)$ & $36(17-83)$ & $1.01(1.007-1.018)$ & $<0.001$ \\
\hline Leucocytes $\left(\times 10^{9}\right.$ cells $\left./ \mathrm{L}\right)$ & $12.9(9.5-15.4)$ & $7.8(6-9.8)$ & $1.14(1.035-1.258)$ & 0.008 \\
\hline Eosinophils (cells $/ \mu \mathrm{L}$ ) & $650(520-1410)$ & $220(100-400)$ & $1.01(1.002-1.004)$ & $<0.001$ \\
\hline \multicolumn{5}{|l|}{ Daptomycin therapy } \\
\hline Daily dose (mg; median, IQR) & $700(700-700)$ & $700(600-800)$ & $1(0.99-1.01)$ & 0.719 \\
\hline Length (days; median, IQR) & $19(12-25)$ & $7(4-15)$ & $1.08(1.03-1.14)$ & 0.005 \\
\hline$\leq 14$ days & $3(27)$ & $162(74)$ & 1 & \\
\hline$>14$ days & $8(73)$ & $56(26)$ & $7.71(1.98-30.09)$ & 0.003 \\
\hline${ }^{1} \mathrm{TCDD}$ (g; median, IQR) & $13.2(8.4-17.5)$ & $5.1(2.4-11.2)$ & $1.11(1.03-1.19)$ & 0.004 \\
\hline$<10 \mathrm{~g}$ & $3(27)$ & $155(71)$ & 1 & \\
\hline $10-15 \mathrm{~g}$ & $4(36)$ & $39(18)$ & $5.30(1.14-24.66)$ & 0.034 \\
\hline$>15 \mathrm{~g}$ & $4(36)$ & $24(11)$ & $8.61(1.81-40.87)$ & 0.007 \\
\hline Repeated exposure & $2(20)$ & $23(10)$ & $1.88(0.38-9.26)$ & 0.435 \\
\hline
\end{tabular}

Analytical data is presented as median, IQR. The remaining data are presented as $n(\%)$ unless otherwise noted. ${ }^{1}$ TCDD (Total Cumulative Dose of Daptomycin; daily dose X days of treatment; The result was expressed in grams-g-) ${ }^{2}$ Cases without DEP in which creatine kinase values were analyzed had a median of 12 days (IQR 6-19.5) of daptomycin therapy. 
All DEP cases were treated with daptomycin withdrawal and seven $(64 \%)$ with corticosteroid therapy. One patient, who had a delay in diagnosis of DEP and therapy, died because of respiratory failure.

In the univariate analysis (Table 1), factors associated with DEP were advanced age, the presence of comorbidities measured by Charlson score, long treatment with daptomycin and high values of TCDD. Concisely, daptomycin therapy for two weeks or longer was associated with high risk of DEP (HR 7.71, 95\%CI 1.98-30.09), as well as TCDD values $\geq 10 \mathrm{~g}$ (HR 5.30, 95\%CI 1.14-24.66). The presence of blood eosinophilia at the end of daptomycin treatment was significantly higher in DEP cases than in controls $(82 \%$ and $16 \%$, respectively; $p<0.001$ ), as well as leucocyte counts and C-reactive protein values were also higher in DEP cases.

We noted that among older patients aged $\geq 70$ years $(n=123)$, the percentage with DEP $(8.1 \% ; 10 / 123)$ almost doubled the value of the whole cohort. Also, the percentage of cases with DEP increased significantly among cases aged $\geq 70$ years in comparison with the whole cohort either in cases treated for $>14$ days or in those with high values of TCDD (Figure 1).

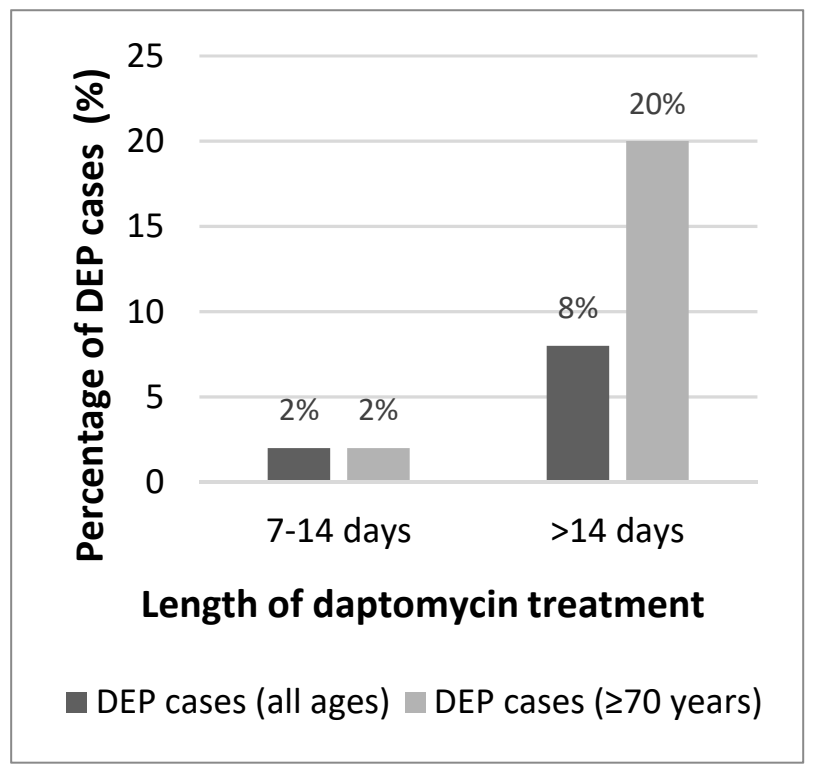

(a)

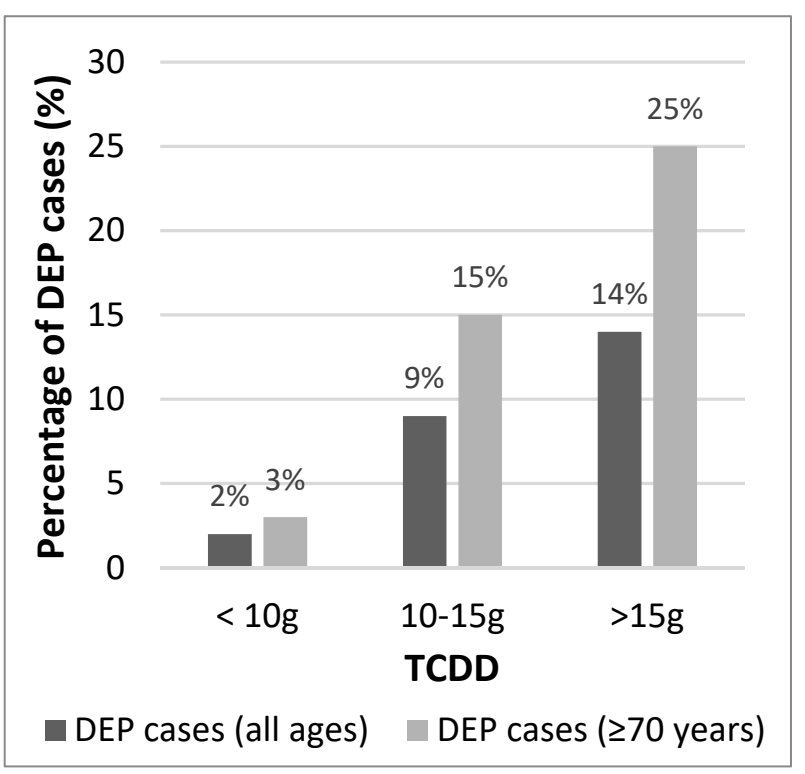

(b)

Figure 1. Percentage of Daptomycin-induced eosinophilic pneumonia (DEP) cases in the whole cohort and in those aged $\geq 70$ years by (a) Length of therapy and by (b) The total cumulative dose of daptomycin (TCDD).

Finally, 25 cases had a re-challenge to daptomycin therapy, and two of these presented promptly with DEP ( $8 \%$ ) by 4 and 8 days after the re-challenge ( 3 and 5 months after the first exposure, respectively). Both cases presented blood eosinophilia after the first course of treatment, having received $>11 \mathrm{~g}$ over $>14$ days. By contrast, among the remaining patients re-challenged with daptomycin, the eosinophilia was only observed at the prior exposure for four patients (17\%).

\section{Discussion}

In the present study we reported the main risk factors for developing DEP in a population with osteoarticular infections, providing important new information that may be helpful to clinicians.

Daptomycin has been reported as the leading cause of drug-induced eosinophilic pneumonia [14], and clinicians should maintain a high index of suspicion for DEP because of its potential severity. Although most of cases in our series were resolved by daptomycin 
withdrawal and corticosteroid therapy, one patient died, which illustrates the inherent risk of failing to identify DEP promptly.

Daptomycin use for the treatment of osteoarticular infection is currently recommended mainly against staphylococcal infections and as initial induction antimicrobial therapy $[1,2]$. In contrast with the high activity of daptomycin in animal and in vitro studies, its clinical efficacy reported from non-comparative studies appeared to be quite similar to other therapies $[5,15,16]$. However, prolonged therapy at higher doses than usual seems to be increased in recent years. Our cases were treated with daptomycin for a median of 19 days and resulted in DEP proportions of $4.8 \%$ overall and $8.1 \%$ among those aged $\geq 70$ years. This data may seem high compared with previous experiences and without placing it in context. Thus, populations with 102 cases of infective endocarditis and 43 cases of complex osteoarticular infections that received high doses of daptomycin (median $8.2 \mathrm{mg} / \mathrm{kg} / \mathrm{d}$ ) for long periods (20-80 days), the authors showed 3\% and $4.6 \%$ developed $\mathrm{DEP}$, respectively $[17,18]$. These are consistent with our results given that the populations in both studies were younger (mean age 61.5 years) than in the present study.

Taking all the previous into account, the prolonged therapy with daptomycin against osteoarticular infections or the use of higher doses than usual should be considered on the basis of a list of pros and cons. Probably, the efficacy of daptomycin therapy is related with its anti-biofilm activity and can be benefited through an initial intensive phase of treatment (i.e., 7-14 days). Further therapy should be balanced with inconveniences derived from its use; indeed, monitoring for daptomycin toxicity appears crucial in long therapies and includes not only the risk for DEP but also other adverse events such as rhabdomyolysis. In our experience, performance of chest- $X$ ray was useful to identify DEP and thus, it appears as valid screening to be interpreted together with other clinical signs and analytical parameters.

To our knowledge, no previous studies had been performed to analyze the risk factors of developing DEP. We identified advanced age, high values of Charlson comorbidity index, length of daptomycin therapy and TCDD as the main risk factors for DEP. Of interest, we show that patients older than 70 years, which commonly have more underlying diseases, are at higher risk of DEP; however, further research is needed to evaluate the importance of particular comorbidities in increasing the risk of DEP.

Regarding cumulative dosages of daptomycin and long therapies, our results seem to be consistent with previous works. Hirai et al. [19] reported 40 cases of DEP, $73 \%$ of them received a daptomycin dosage $>6 \mathrm{mg} / \mathrm{kg} / \mathrm{d}$ for a median of 14.8 days, whereas the remaining cases were treated with daptomycin at $\leq 6 \mathrm{mg} / \mathrm{kg} / \mathrm{d}$ for a median of 23 days. In a systematic review of DEP cases the mean length of daptomycin therapy was 2.8 weeks and main indication for treatment was osteoarticular infection [20]. Overall, it seems that higher risk of DEP is not only dose dependent but also time-dependent. We therefore recommend monitoring the cumulative dose of daptomycin, which is a product of the dosage and length of therapy, rather than considering either variable separately. In our experience, clinicians should be cautious when the TCDD is $\geq 10 \mathrm{~g}$, and particularly if it increases to $\geq 15 \mathrm{~g}$, which can be easily attained after 2 weeks of treatment in patients receiving high doses.

Cases with DEP at the end of therapy had higher blood eosinophil counts and more often eosinophilia than controls, a fact that has been mainly reported previously [20,21]. Of interest, we noted a scenario in which severe DEP occurred shortly after a re-challenge with daptomycin, indicating that a drug hypersensitivity mechanism may be play. These cases presented with eosinophilia at the end of their previous course of daptomycin, a finding that was rarely observed in patients given a rechallenge without developing DEP. This clinical situation has been poorly reported to date [22], but it seems that eosinophilia during daptomycin therapy should prompt clinicians to consider avoiding further drug exposure.

The main limitations of the study are those inherent to the retrospective design. Generalizability is affected because patients were recruited from a single center and because the cohort mostly comprised elderly people with heterogeneous clinical presentations of 
osteoarticular infections. Also, unfortunately, our sample size of DEP cases was small to allow subgroup analyses or to design other comparative study. These factors must be factored when considering other heterogeneous populations. Irrespective of these shortcomings, however, we believe that our results provide information that can be led to improved management of daptomycin therapy.

\section{Materials and Methods}

\subsection{Study Design, Setting, and Inclusion/Exclusion Criteria}

This retrospective cohort study was performed at the Bone and Joint Infection Unit of the Hospital Universitari Bellvitge between January 2014 and December 2018. We included all patients with osteoarticular infection (prosthetic joint infection, septic arthritis and osteomyelitis), aged $\geq 18$ years, and treated at least with one dose of daptomycin because of empirical treatment or guided therapy addressed to Gram-positive microorganisms. Polymicrobial osteoarticular infections treated with daptomycin in combination with other antibiotics were also included. We excluded cases attended in our Bone and Joint Infection Unit that received daptomycin due to causes different than osteoarticular infections (i.e., catheter-related sepsis).

To identify risk factors for DEP, cases were divided into two groups: Those who developed DEP and those without DEP.

Written informed consent was considered unnecessary for the study, as it was a retrospective analysis of our clinical practice. Data of patients were anonymized for the purposes of this analysis. Confidential information of patients was protected according National and European normative. This manuscript has been revised for its publication by Research Ethics Committee of Bellvitge University Hospital (PR097/21).

\subsection{Definitions and Clinical Data}

All cases fulfilled the main diagnostic criteria for each osteoarticular infection, including those with prosthetic joint infection or osteoarthritis, with or without an orthopedic device.

The modified diagnostic criteria established by Philips et al. were used to define DEP [23], which required exposure to daptomycin with the following features: fever, dyspnea with increased oxygen requirement or requiring mechanical ventilation, new infiltrates on chest X-ray or computed tomography, and clinical improvement following daptomycin withdrawal. In accordance with these criteria, we did not require the previous pre-requisite of a bronchoalveolar lavage with $>25 \%$ eosinophils.

Demographic, clinical, radiological and analytical data were collected for the included cases. Chronic heart failure, chronic pulmonary disease and chronic kidney disease were defined according to accepted criteria. The total cumulative dose of daptomycin (TCDD) was defined as daily dose of daptomycin $\times$ days of treatment; the result was expressed in grams $(\mathrm{g})$.

\subsection{Statistical Analysis}

Data were analyzed using Stata software (version 16.0, Stata Corporation, College Station, TX, USA). Categorical variables are described by counts and percentages, while medians and interquartile ranges (IQRs) are used to summarize continuous variables.

Univariate analysis was performed to screen the risk factors for DEP, and logistic regression models were built to estimate unadjusted hazard ratios (HR). In all situations, $p$-values of $<0.05$ were considered to be statistically significant.

\section{Conclusions}

In conclusion, main factors associated with DEP were advanced age, high values of Charlson score, longer treatments and high total cumulative doses of daptomycin. Particularly, clinicians should take care in cases with cumulative doses greater than $10 \mathrm{~g}$, which can be achieved after 2 weeks of daptomycin therapy. In this high risk population and after the beginning of treatment, performing a chest-X ray is useful to identify DEP. 
Where eosinophilia has previously occurred with daptomycin exposure, further drug challenges should be considered with great care to minimize the risk of DEP.

Author Contributions: L.S.-B., B.V., M.U., E.B., A.P., A.R., I.B., J.A. and O.M. contributed in the supervision of the clinical cases, data collection, and interpretation; L.S.-B. and O.M. elaborated the study design; L.S.-B. performed the analysis of the data and wrote the first draft of the manuscript. All authors have read and agreed to the published version of the manuscript.

Funding: L.S-B. was supported with a grant of the Ministerio de Ciencia, Innovación y Universidades (FPU (18/02768). This research did not receive any specific grant from funding agencies in the public, commercial, or not-for-profit sectors. This research received no external funding.

Institutional Review Board Statement: The study was conducted according to the guidelines of the Declaration of Helsinki, and approved by the Ethics Committee of Bellvitge University Hospital (protocol code PR097/21).

Informed Consent Statement: Patient consent was waived due to the retrospective nature of the study on the usual clinical practice.

Data Availability Statement: The data presented in this study are available on request from the corresponding author (omurillo@bellvitgehospital.cat).

Acknowledgments: We thank Dolors Rodriguez-Pardo from Hospital Vall d'Hebron, Isabel Mur from Hospital de la Santa Creu i Sant Pau and Rosa Escudero from Hospital Ramon y Cajal for their collaboration with the manuscript. We thank Michael Maudsley for revising the English manuscript. We thank CERCA Program/Generalitat de Catalunya for institutional support. The preliminary results of this study were reported in part at the 30th European Congress of Clinical Microbiology \& Infectious Diseases (Paris, France, 2020).

Conflicts of Interest: The authors declare no conflict of interest.

\section{References}

1. Osmon, D.R.; Berbari, E.F.; Berendt, A.R.; Lew, D.; Zimmerli, W.; Steckelberg, J.M.; Rao, N.; Hanssen, A.; Wilson, W.R. Diagnosis and management of prosthetic joint infection: Clinical practice guidelines by the infectious diseases Society of America. Clin. Infect. Dis. 2013, 56, 1-25. [CrossRef]

2. Ariza, J.; Cobo, J.R.; Artetxe, J.B.-E.; de Benito Hernandez, N.; Tuneu, G.B.; Cabo, J.; Perez-Cardona, P.C.; Moreno, J.E.; Horcajada Gallego, J.P.; Lora-Tamayo, J.; et al. Management of Prosthetic Joint Infections. Clinical Practice Guidelines by the Spanish Society of Infectious Diseases and Clinical Microbiology (SEIMC). Available online: https://seimc.org/contenidos/gruposdeestudio/ geio/dcientificos/documentos/geio-dc-2017-Guia_IPAS_EIMC.pdf (accessed on 1 April 2021).

3. Falagas, M.E.; Giannopoulou, K.P.; Ntziora, F.; Papagelopoulos, P.J. Daptomycin for treatment of patients with bone and joint infections: A systematic review of the clinical evidence. Int. J. Antimicrob. Agents 2007, 30, 202-209. [CrossRef] [PubMed]

4. Chang, Y.-J.; Lee, M.S.; Lee, C.-H.; Lin, P.-C.; Kuo, F.-C. Daptomycin treatment in patients with resistant staphylococcal periprosthetic joint infection. BMC Infect. Dis. 2017, 17, 736. [CrossRef] [PubMed]

5. Lora-Tamayo, J.; Parra-Ruiz, J.; Rodríguez-Pardo, D.; Barberán, J.; Ribera, A.; Tornero, E.; Pigrau, C.; Mensa, J.; Ariza, J.; Soriano, A. High doses of daptomycin $(10 \mathrm{mg} / \mathrm{kg} / \mathrm{d})$ plus rifampin for the treatment of staphylococcal prosthetic joint infection managed with implant retention: A comparative study. Diagn. Microbiol. Infect. Dis. 2014, 80, 66-71. [CrossRef] [PubMed]

6. He, W.; Zhang, Y.; Chen, H.; Zhao, C.; Wang, H. Efficacy and safety of daptomycin for the treatment of infectious disease: A meta-analysis based on randomized controlled trials. J. Antimicrob. Chemother. 2014, 69, 3181-3189. [CrossRef] [PubMed]

7. Benvenuto, M.; Benziger, D.P.; Yankelev, S.; Vigliani, G. Pharmacokinetics and Tolerability of Daptomycin at Doses up to 12 Milligrams per Kilogram of Body Weight Once Daily in Healthy Volunteers. Antimicrob. Agents Chemother. 2006, 50, 3245-3249. [CrossRef]

8. Silverman, J.A.; Mortin, L.I.; VanPraagh, A.D.G.; Li, T.; Alder, J. Inhibition of Daptomycin by Pulmonary Surfactant: In Vitro Modeling and Clinical Impact. J. Infect. Dis. 2005, 191, 2149-2152. [CrossRef] [PubMed]

9. Allen, J.N. Drug-induced eosinophilic lung disease. Clin. Chest Med. 2004, 25, 77-88. [CrossRef]

10. Hayes, D.; Anstead, M.I.; Kuhn, R.J. Eosinophilic pneumonia induced by daptomycin. J. Infect. 2007, 54, e211-e213. [CrossRef]

11. Cobb, E.; Kimbrough, R.C.; Nugent, K.M.; Phy, M.P. Organizing Pneumonia and Pulmonary Eosinophilic Infiltration Associated with Daptomycin. Ann. Pharm. 2007, 41, 696-701. [CrossRef]

12. Lal, Y.; Assimacopoulos, A.P. Two cases of daptomycin-induced eosinophilic pneumonia and chronic pneumonitis. Clin. Infect. Dis. 2010, 50, 737-740. [CrossRef] [PubMed]

13. Miller, B.A.; Gray, A.; LeBlanc, T.W.; Sexton, D.J.; Martin, A.R.; Slama, T.G. Acute Eosinophilic Pneumonia Secondary to Daptomycin: A Report of Three Cases. Clin. Infect. Dis. 2010, 50, e63-e68. [CrossRef] [PubMed]

14. Bartal, C.; Sagy, I.; Barski, L. Drug-induced eosinophilic pneumonia. Medicine 2018, 97, e9688. [CrossRef] [PubMed] 
15. Saleh-Mghir, A.; Muller-Serieys, C.; Dinh, A.; Massias, L.; Crémieux, A.-C. Adjunctive Rifampin Is Crucial to Optimizing Daptomycin Efficacy against Rabbit Prosthetic Joint Infection Due to Methicillin-Resistant Staphylococcus aureus. Antimicrob. Agents Chemother. 2011, 55, 4589-4593. [CrossRef] [PubMed]

16. John, A.-K.; Baldoni, D.; Haschke, M.; Rentsch, K.; Schaerli, P.; Zimmerli, W.; Trampuz, A. Efficacy of Daptomycin in ImplantAssociated Infection Due to Methicillin-Resistant Staphylococcus aureus: Importance of Combination with Rifampin. Antimicrob. Agents Chemother. 2009, 53, 2719-2724. [CrossRef] [PubMed]

17. Durante-Mangoni, E.; Andini, R.; Parrella, A.; Mattucci, I.; Cavezza, G.; Senese, A.; Trojaniello, C.; Caprioli, R.; Diana, M.V.; Utili, R. Safety of treatment with high-dose daptomycin in 102 patients with infective endocarditis. Int. J. Antimicrob. Agents 2016, 48, 61-68. [CrossRef] [PubMed]

18. Roux, S.; Valour, F.; Karsenty, J.; Gagnieu, M.-C.; Perpoint, T.; Lustig, S.; Ader, F.; Martha, B.; Laurent, F.; Chidiac, C.; et al. Daptomycin $>6 \mathrm{mg} / \mathrm{kg} /$ day as salvage therapy in patients with complex bone and joint infection: Cohort study in a regional reference center. BMC Infect. Dis. 2016, 16, 83. [CrossRef]

19. Hirai, J.; Hagihara, M.; Haranaga, S.; Kinjo, T.; Hashioka, H.; Kato, H.; Sakanashi, D.; Yamagishi, Y.; Mikamo, H.; Fujita, J. Eosinophilic pneumonia caused by daptomycin: Six cases from two institutions and a review of the literature. J. Infect. Chemother. 2017, 23, 245-249. [CrossRef]

20. Uppal, P.; LaPlante, K.L.; Gaitanis, M.M.; Jankowich, M.D.; Ward, K.E. Daptomycin-induced eosinophilic pneumonia-a systematic review. Antimicrob. Resist. Infect. Control 2016, 5, 55. [CrossRef] [PubMed]

21. Higashi, Y.; Nakamura, S.; Tsuji, Y.; Ogami, C.; Matsumoto, K.; Kawago, K.; Tokui, K.; Hayashi, R.; Sakamaki, I.; Yamamoto, Y. Daptomycin-induced eosinophilic pneumonia and a review of the published literature. Intern. Med. 2018, 57, 253-258. [CrossRef]

22. Nickerson, M.; Bhargava, A.; Kale-Pradhan, P. Daptomycin-associated eosinophilic pneumonia with rechallenge: A case report. Int. J. Clin. Pharm. 2017, 55, 521-524. [CrossRef] [PubMed]

23. Phillips, J.; Cardile, A.P.; Patterson, T.F.; Lewis, J.S. Daptomycin-induced acute eosinophilic pneumonia: Analysis of the current data and illustrative case reports. Scand. J. Infect. Dis. 2013, 45, 804-808. [CrossRef] [PubMed] 